\title{
Temporal changes in the frequency of colicinogeny in Escherichia coli from house mice
}

\author{
David M. Gordon, ${ }^{1}$ Margaret A. Riley ${ }^{2}$ and Theodora Pinou ${ }^{2}$ \\ Author for correspondence: David M. Gordon. Tel: +6126249 3552. Fax: +61262495573. \\ e-mail : David.Gordon@anu.edu.au
}

\author{
1 Division of Botany and \\ Zoology, Australian \\ National University, \\ Canberra, ACT 0200, \\ Australia \\ 2 Department of Biology, \\ Osborn Memorial \\ Laboratories, Yale \\ University, PO Box 6666, \\ New Haven, Connecticut, \\ 06511-7444, USA
}

\begin{abstract}
Escherichia coli was isolated from feral house mice (Mus domesticus) during the course of a mouse plague in the state of Victoria, Australia. The isolates were characterized for the production of colicins and their resistance to the cooccurring colicins. Of the $\mathbf{4 4 7}$ isolates examined, $59 \%$ were found to be colicinogenic. Phenotypic and PCR-based genotypic methods were used to determine the types of colicins being produced. Colicin $E 2$ was the most common, representing $\mathbf{2 7} \%$ of the colicin-producing isolates. Colicin la was produced by $3 \%$ of the colicinogenic isolates. The remaining colicins could not be identified, but phenotypic and PCR data argue that at least nine different colicin types are present in this collection of $E$. coli. The frequency of colicinogenic isolates declined from $71 \%$ to $43 \%$ over the 7 months of the study. All colicin types appeared to decline in frequency. Concurrently, the resistance of isolates to colicin E2 increased from about $50 \%$ to $70 \%$. Two hypotheses are proposed to explain the decline in the frequency of colicinogeny in this population of $E$. coli. The first relates to the within-host interactions occurring among colicinogenic, colicin-susceptible and colicinresistant populations within a host. The second relates to the among-host interactions between susceptible and colicinogenic populations and the effect of host population densities on these interactions.
\end{abstract}

Keywords: Escherichia coli, colicinogeny, colicin resistance, ecology, mouse

\section{INTRODUCTION}

The production of antibacterial compounds known as colicins is a common trait in Escherichia coli (Riley \& Gordon, 1992, 1996). Although the term colicin encompasses a diverse class of antimicrobial agents, with over twenty types described, they share a number of features (Pugsley, 1984; Riley \& Gordon, 1996). Colicins are encoded on plasmids, the genes are usually repressed and are tightly linked with an immunity gene, whose product confers specific immunity to that colicin. Colicin production results in the killing of neighbouring cells that are not immune or resistant to the colicin. The high frequency of colicin producers in most natural populations of E. coli, in light of the costs of colicinogeny, argues that colicins play some role in E. coli population dynamics (Riley \& Gordon, 1996). The evidence for this role comes from many sources.

Abbreviations: MLEE, multi-locus enzyme electrophoresis; RAPD, randomly amplified polymorphic DNA.
Theoretical studies have demonstrated that producing colicins enhances the invasion and establishment success of a clone (Levin, 1988; Frank, 1994; Durrett \& Levin, 1997). In vitro studies have also demonstrated that being colicinogenic increases the likelihood that a clone will successfully invade a colicin-sensitive population (Chao \& Levin, 1981). The evidence coming from in vivo studies has been more equivocal but some of the studies have suggested that colicinogeny does improve the establishment success of strains (Tad \& Hurst, 1961; Cooke et al., 1972; Craven \& Barnum, 1971). Despite this evidence, some workers have suggested that colicins may not function in intra-specific competition but may have other roles (Luria \& Suit, 1987; Feldgarden et al., 1995).

One of the strongest lines of evidence against a role of colicins as an anti-competitor mechanism is the high frequency of resistance to colicins that has been observed. Resistance is due to the loss of the cell surface receptors to which colicins bind (Pugsley, 1984). Most strains of $E$. coli are resistant to most colicins (Riley \& 
Gordon, 1992). The resistance data argue against a role for colicins in intra-specific competition. However, previous studies examining the diversity and abundance of colicins and the level of colicin resistance in $E$. coli have been based on ad hoc collections of strains (Riley $\&$ Gordon, 1996). No previous studies have described the frequency of colicinogeny and resistance to the cooccurring colicins in a population of potentially interacting clones of E. coli over time. This was the purpose of this study. To this end, over 440 isolates of $E$. coli were collected from feral house mice at 2 localities in Australia over a 7 month period. Assays for colicin production and resistance in these strains reveal the potential for complex interactions between colicin producers and their resistant and sensitive counterparts.

\section{METHODS}

Study site and host collection. Mus domesticus were collected from two wheat-growing properties (Stone and Symes) $15 \mathrm{~km}$ apart near the town of Walpeup in the Mallee district of north western Victoria, Australia. In excess of 500 mice were collected on 6 occasions during the summer and autumn of $1993 / 94$ by establishing trapping transects in a single field on each property. Further details of the age and sex structure of the mouse population are presented by Gordon (1997).

Isolation and characterization of bacteria. A single clone was isolated from every mouse by sampling the upper colon contents using a sterile swab. Following purification all isolates were tested for growth on minimal lactose and minimal citrate agar plates. The $\mathrm{Lac}^{+} \mathrm{Cit}^{-}$isolates were presumed to be $E$. coli and the identifications were subsequently confirmed using additional biochemical criteria. Further details of the clone isolation and identification procedures are given by Gordon (1997).

The strains were characterized genotypically using a PCRbased randomly amplified polymorphic DNA (RAPD) method (two 10-mer primers) and multi-locus enzyme electrophoresis (MLEE) assays (13 loci). Further details of these methods are given by Gordon (1997). RAPD and MLEE results were pooled and out of the $447 \mathrm{E}$. coli isolates examined, 88 unique RAPD/MLEE haplotypes were identified. Plasmid DNA from a representative of each RAPD/MLEE haplotype was isolated using the Wizard Plus Miniprep DNA Purification System (Promega) following the manufacturer's protocol. The resulting product was visualized on ethidium-bromide-stained $0.5 \%$ agarose gels, together with a ladder of six knownmolecular-mass plasmids.

Determination of colicin phenotypes. All 447 isolates were assayed for colicin production using a method modified from Pugsley \& Oudega (1987). The medium used was LB (Power \& McCuen, 1988), as broth, soft agar (7 $\mathrm{g}$ agar $\mathrm{l}^{-1}$ ) or solidified in plates $\left(15 \mathrm{~g} \mathrm{l}^{-1}\right) \mathrm{A} 1 \mathrm{ml}$ aliquot of an overnight LB culture was transferred to a flask containing $10 \mathrm{ml} \mathrm{LB}$ broth. The cultures were incubated for $1 \mathrm{~h}\left(37^{\circ} \mathrm{C}\right.$ and 200 r.p.m.), after which time mitomycin $\mathrm{C}$ was added to produce a final concentration of $0 \cdot 1-0.2 \mu \mathrm{g} \mathrm{ml}^{-1}$. After an additional $4 \mathrm{~h}$ incubation $1.5 \mathrm{ml}$ of the culture was removed and the cells pelleted by centrifugation $(5 \mathrm{~min}, 14260 \mathrm{~g}$ ). The supernatant was transferred to a microfuge tube containing $50 \mu \mathrm{l}$ chloroform. The tubes were vortexed and the remaining cellular debris pelleted by centrifugation. Extracts were stored at $5^{\circ} \mathrm{C}$ for a maximum of 1 week. Soft agar lawns of the colicinsensitive E. coli $\mathrm{K}-12$ strains $\mathrm{CSH} 50$ and BZB1011 were prepared and $10 \mu \mathrm{l}$ of each colicin extract were spotted onto lawns of the indicator strains. The plates were incubated overnight at $37^{\circ} \mathrm{C}$ and then scored. The production of a zone of clearing indicates that the isolate is producing either a colicin or serving as a host to a temperate bacteriophage. To distinguish between these two possibilities the following tests were performed. First, the extract was serially diluted (twofold dilutions) and the dilutions spotted onto lawns of BZB1011. If the zones of clearing became increasingly opaque without the appearance of individual phage-like plaques then the strain was considered to be a colicin producer. Second, the crude extract was passed through a Microcon $100000 \mathrm{Da}$ microconcentrator (Amicon). Colicins usually have a molecular mass less than $100000 \mathrm{Da}$ whilst phage tend to exceed this value; therefore if the purified extract produces a zone of clearing on a sensitive lawn this suggests that the strain being tested is colicinogenic and not lysogenic.

Determination of colicin identity. Preliminary identification of the colicins being produced was made using a phenotypic approach (Pugsley \& Oudega, 1987). Crude colicin extracts of all 246 colicinogenic isolates were spotted onto lawns of $E$. coli J53 strains harbouring different known colicin plasmids. Strains are immune to the colicin that they produce. Therefore, if a colicin extract produces zones of clearing on all but one of the test lawns, then the unknown colicin is likely to be the same as that produced by the unaffected test strain. Multiple isolates of the same RAPD/MLEE haplotype gave similar phenotypic results. In the few cases where isolates did not produce similar results, it was because one or more of the isolates failed to produce colicins. Therefore, to reduce the number of strains that needed to be screened, only a single representative of each haplotype was used in attempts to confirm the identity of the colicins using a PCR-based approach.

The following $5^{\prime}$ and $3^{\prime}$ primer pairs were chosen based upon the phenotypic results (product size in parentheses): ColE2, $5^{\prime}$ TTT ATG AGC GGT GGC GAT $3^{\prime}, 5^{\prime}$ TCG GGT TAC TGC GTT GCT AA 3' (2221 bp); Colla, 5' GGA ATT CTC TTG ACA TGC CAT TTT CTC CTT 3', 5' GGA ATT CCC GCC ACA TCT TTT TGC TGT CCA 3' (2510 bp); ColA, 5' ACA GCG TGG CGG CAG GTA GCC GCT CAG C 3', 5' CCG GAA GGC CTG TCA GAT TAA TGG CCA CC 3 (2025 bp); ColE6, 5' CGA TTT GCC CAT GAC CCA ATG GCT GGC GG 3', 5' GGA GGC TCC AGC GTT CAT CCA TGA ACA C 3' (862 bp); ColE7, 5' CCC TCC CTG ACT TGA CAG AGA AAA TAA TGG CG 3', $3^{\prime}$ GCC TCT GTG TAA TCA CTA ATA CTA TTT TTC AG 3' (1894 bp). In addition, some strains were screened with a primer specific to the immunity region of the ColE2 gene cluster. The primer pair used was: $5^{\prime}$ GCC CGC TCT GCG TTT TCT AA 3', 5' CAA CAG CTG AAG TGA CCG GA 3' (189 bp).

The product of the Wizard Miniprep System was used for the template DNA. Reaction volumes were $20 \mu \mathrm{l}$ and the reaction mix consisted of: $67 \mathrm{mM}$ Tris/HCl pH 8.8, $16.6 \mathrm{mM}$ $\left(\mathrm{NH}_{4}\right)_{2} \mathrm{SO}_{4}, 1.5 \mathrm{mM} \mathrm{MgCl}, 0.2 \mathrm{mM}$ dNTPs, $0.45 \%$ Triton X$100,0 \cdot 2 \mathrm{mg}$ gelatin $\mathrm{ml}^{-1}, 3 \cdot 1 \mathrm{ng}$ primer $\mu \mathrm{l}^{-1}$. PCR amplification conditions were: 5 cycles of $92^{\circ} \mathrm{C}$ for $10 \mathrm{~s}, 40^{\circ} \mathrm{C}$ for $120 \mathrm{~s}$ and $72{ }^{\circ} \mathrm{C}$ for $90 \mathrm{~s}$; then 35 cycles of $92^{\circ} \mathrm{C}$ for $5 \mathrm{~s}, 55^{\circ} \mathrm{C}$ for $25 \mathrm{~s}$ and $72{ }^{\circ} \mathrm{C}$ for $90 \mathrm{~s}$; and 1 cycle of $92^{\circ} \mathrm{C}$ for $10 \mathrm{~s}, 45^{\circ} \mathrm{C}$ for $20 \mathrm{~s}$ and $72^{\circ} \mathrm{C}$ for $300 \mathrm{~s}$. The annealing temperature for the ColA, ColE6 and ColE7 screening was $45^{\circ} \mathrm{C}$ and $55^{\circ} \mathrm{C}$ for the ColE2 immunity screening.

Colicin resistance. To reduce the number of strains which needed to be screened from $264 \times 447$ to a more manageable number only a single representative of each RAPD/MLEE haplotype was used to assess colicin resistance in this 
population. Crude extracts of all 36 colicinogenic haplotypes were prepared and spotted (undiluted) onto lawns of all 88 haplotypes in a manner similar to that used to screen for colicinogeny. A haplotype was considered to be resistant if the undiluted colicin extract failed to cause a decrease in cell density where the extract was applied. Resistance was scored in two ways. First, for each of the 36 colicinogenic haplotypes the fraction of the 88 haplotypes which were resistant to that colicin was determined. This score can be thought of as a measure of colicin efficacy; or the fraction of the $E$. coli population that this colicin can kill. Second, for each of the $\mathbf{8 8}$ haplotypes the fraction of the 36 colicinogenic strains to which it was resistant was determined. This provides, for each strain, a measure of how likely it is for this strain to be killed by one of the colicins being produced in this population. These resistance estimates were adjusted to take into account the fact that, in some cases, the same colicin was being produced by several different haplotypes. For example, if a haplotype was a colicin Ia producer, it would be immune to itself and to any other haplotypes producing colicin Ia. Therefore, to determine the fraction of haplotypes resistant to colicin Ia, the numerator would represent the number of strains that are resistant to that colicin, while the denominator would be the number of haplotypes known not to be producing colicin Ia. The titre of colicin produced by each of the 36 colicinogenic haplotypes was estimated by serially diluting (twofold dilutions) the crude extract and determining the highest dilution which produced a zone of clearing on a sensitive lawn.

The results demonstrated that colicin E2 was the most common colicin being produced in this collection of strains. The susceptibility of all isolates $(n=326)$ not harbouring the ColE2 plasmid to colicin E2 was determined in the following manner. Thirteen haplotypes produced colicin E2. Each of the non-E2 producing isolates was tested for resistance to undiluted extracts from a representative of each of the 13 ColE2 haplotypes. Resistance was quantified as the fraction of the 13 extracts to which the isolate was resistant.

\section{RESULTS}

\section{Colicin diversity}

Of the 88 unique RAPD/MLEE haplotypes, 36 were found to be colicinogenic. Testing crude lysates from these colicinogenic strains on lawns of strains harbouring known colicin plasmids revealed seven phenotypic patterns (Table 1 ). Screening all 88 haplotypes using a PCR approach revealed that 17 of the colicinogenic strains had the ColE2 gene cluster, whilst ColIa genes were detected in 6 of the colicinogenic strains (Table 1). ColIa and ColE2 genes were found to co-occur in one strain (strain 125, Table 1). None of the non-colicinogenic strains produced positive results with either the ColE2 or Colla primer pairs. Strains harbouring the ColE2 gene cluster accounted for $53 \%$ of the 36 colicinogenic haplotypes and $27 \%$ of the colicinogenic isolates. Strains with the ColIa gene cluster represented $19 \%$ of the colicinogenic haplotypes and $3 \%$ of the colicinogenic isolates.

The colicins produced by half of the colicinogenic E. coli haplotypes have been unambiguously identified. The identity of the remaining colicins is unknown. No positive results were obtained when the colicinogenic strains were screened using primer pairs specific for
ColA, ColE7 or ColE6. Recently, ColE2/E7 chimeras have been detected (Tan \& Riley, 1997). These chimeras are thought to be derived from a recombination event between the ColE2 gene cluster and the ColE7 plasmid. This has resulted in the ColE2 gene cluster being located on a $6.1 \mathrm{~kb}$ plasmid. All of the ColE2-positive E. coli haplotypes found in this study are examples of this chimera. Another nine colicinogenic haplotypes had a plasmid of this size (Table 1), while only one of the noncolicinogenic haplotypes harboured this size plasmid. As some of the unidentified colicinogenic strains had an E7 or E2/E7 phenotype and a plasmid of the appropriate size it is possible that these strains are also chimeras. However, no positive results were obtained when these strains were screened with a primer specific to the ColE2 immunity gene. Thus, if they are chimeras, they are of a different sort than has been recently characterized.

The lack of any phenotype for some of the strains suggests that these strains are producing an as yet undescribed colicin, or are producing more than one type of colicin. Multiple colicin production has been confirmed for one strain (125) which produces ColE2 and Colla (Table 1). Strains 135, 139 and 183 have the ColE2 genes, but the test strain harbouring a ColE2 plasmid is not immune to the extracts produced by these strains (Table 1). This is a result consistent with the production of more than one colicin. It is not known whether strains $5,170,184$ and 234 are producing a novel colicin or multiple colicins.

The combined results of the phenotypic and PCR analyses argue that there are at least nine colicin types present in this collection of strains (Table 1). There were seven different phenotype patterns observed and three different genotypes, combining the two results in nine different phenotype/genotype combinations.

\section{Distribution of colicinogeny in relation to haplotype similarity}

The 17 E. coli haplotypes harbouring the ColE2 plasmid are, on average, not more genetically similar than are any other 17 haplotypes drawn at random [randomization test (Wexler et al., 1995) : probability of observing a smaller mean similarity, $P>0.47]$. By contrast, the seven haplotypes bearing the Colla plasmid are more similar than would be expected to occur by chance $(P<0 \cdot 001)$.

\section{Frequency of colicinogeny: spatial, temporal and host effects}

Of the 447 isolates, $59 \%$ were colicinogenic. There was a significant difference between the two localities in the frequency of colicinogenic isolates (contingency table analysis: $\left.\chi_{(1,445)}^{2}=22 \cdot 4, P<0.001\right) ; 48 \%$ of isolates from the Stone locality were colicin producers and $70 \%$ of isolates from Symes were colicinogenic. The frequency of colicinogenic isolates did not vary with the age or sex of the host from which the isolates were collected [sex, $\chi_{(1,441)}^{2}=0.091, P>0.76$; age, $\chi_{(2,441)}^{2}=4.86, P>0.08$; sex/age interaction, $\left.\chi_{(2,441)}^{2}=1 \cdot 08, P>0.58\right]$. 
Table 1. Characteristics of colicinogenic $E$. coli haplotypes isolated from feral house mice, M. domesticus

\begin{tabular}{|c|c|c|c|c|c|c|}
\hline Strain & Phenotype* & ColE2 $†$ & ColIa† & $6 \mathrm{~kb}$ plasmid $\neq$ & Frequency $(\%) \$$ & Efficacy $(\%) \|$ \\
\hline 79 & $\mathrm{E} 2$ & + & - & + & 0.89 & 88 \\
\hline 191 & E2 & + & - & + & 0.22 & 88 \\
\hline 236 & E2 & + & - & + & $5 \cdot 37$ & 64 \\
\hline 266 & E2 & + & - & + & 0.67 & 63 \\
\hline 356 & E2 & + & - & + & $0 \cdot 22$ & 65 \\
\hline 190 & E2 & + & - & + & $0 \cdot 22$ & 88 \\
\hline 163 & $\mathrm{E} 2$ & + & - & + & 0.45 & 75 \\
\hline 176 & $\mathrm{E} 2$ & + & - & + & $0 \cdot 22$ & 72 \\
\hline 126 & $\mathrm{E} 2$ & + & - & + & $5 \cdot 82$ & 67 \\
\hline 153 & E2 & + & - & + & $0 \cdot 22$ & 63 \\
\hline 168 & $\mathrm{E} 2$ & + & - & + & $0 \cdot 22$ & 88 \\
\hline 232 & $\mathrm{E} 2$ & + & - & + & $10 \cdot 07$ & 75 \\
\hline 259 & E2 & + & - & + & 0.67 & 67 \\
\hline 135 & None & + & - & + & $1 \cdot 12$ & 17 \\
\hline 139 & None & + & - & + & 0.22 & 36 \\
\hline 183 & None & + & - & + & 0.45 & 33 \\
\hline 125 & None & + & + & + & 0.22 & 71 \\
\hline 157 & IA & - & + & - & 0.22 & 94 \\
\hline 57 & IA & - & + & - & 0.67 & 94 \\
\hline 137 & IA & - & + & - & 0.22 & 88 \\
\hline 225 & IA & - & + & - & 0.22 & 95 \\
\hline 263 & IA & - & + & - & 0.22 & 98 \\
\hline 472 & IA & - & + & - & $0 \cdot 22$ & 89 \\
\hline 243 & A & - & - & + & 0.89 & 51 \\
\hline 113 & E2 E7 & - & - & + & 1.57 & 66 \\
\hline 241 & E2 E7 & - & - & + & 1.79 & 78 \\
\hline 307 & E2 E7 & - & - & + & $2 \cdot 24$ & 74 \\
\hline 383 & E2 E7 & - & - & + & $2 \cdot 68$ & 70 \\
\hline 482 & E2 E7 & - & - & + & 0.22 & 38 \\
\hline 409 & E6 & - & - & + & 6.04 & 51 \\
\hline 479 & E6 & - & - & + & 0.22 & 66 \\
\hline 269 & E7 & - & - & + & $0 \cdot 22$ & 72 \\
\hline 5 & None & - & - & - & $12 \cdot 75$ & 94 \\
\hline 170 & None & - & - & - & 0.67 & 79 \\
\hline 234 & None & - & - & - & $0 \cdot 22$ & 85 \\
\hline 184 & None & - & - & - & 0.22 & 84 \\
\hline
\end{tabular}

* Test strains harbouring these known colicin plasmids were not affected by the colicin produced by the strain (see text for further details).

†Positive/negative result from PCR screening using ColE2- and ColIa-specific primer pairs.

$\ddagger$ Plasmid of this size present/absent.

\$Percentage of the 447 isolates with this haplotype.

|| Percentage of the 88 haplotypes resistant to the colicin produced by the strain.

There was a significant decline in the frequency of colicinogeny over time. The decline was similar at both localities [logistic regression: date, $\chi_{(1,443)}^{2}=14.92$, $P<0.001$; locality, $\chi_{(1,443)}^{2}=11.37, P<0.001$; date / locality interaction, $\left.\chi_{(1,443)}^{2}=0.88, P>0.34\right]$. Pooling the data for both localities revealed that the frequency of colicinogenic isolates declined from $71 \%$ in December to $43 \%$ in June (Fig. 1). This decline did not appear to be restricted to one type of colicin. When the isolates were partitioned into three groups, those producing only colicin E2, all other colicin types and the noncolicinogenic isolates, the frequency of both colicinproducing groups of isolates significantly declined through time.

\section{Susceptibility to co-occurring colicins}

The proportion of the 88 haplotypes resistant to the colicin produced by a particular colicinogenic haplotype varied from $17 \%$ to $98 \%$. For example, $88 \%$ of the 


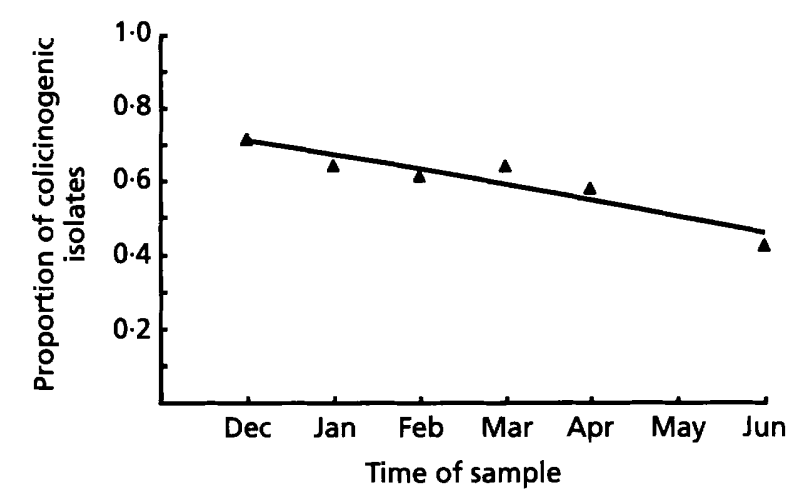

Fig. 1. Change in the frequency of colicinogeny in $E$. coli isolates from $M$. domesticus. The symbols represent the observed frequency of colicinogeny for each sample date. The solid line depicts the change in the frequency as estimated using logistic regression.

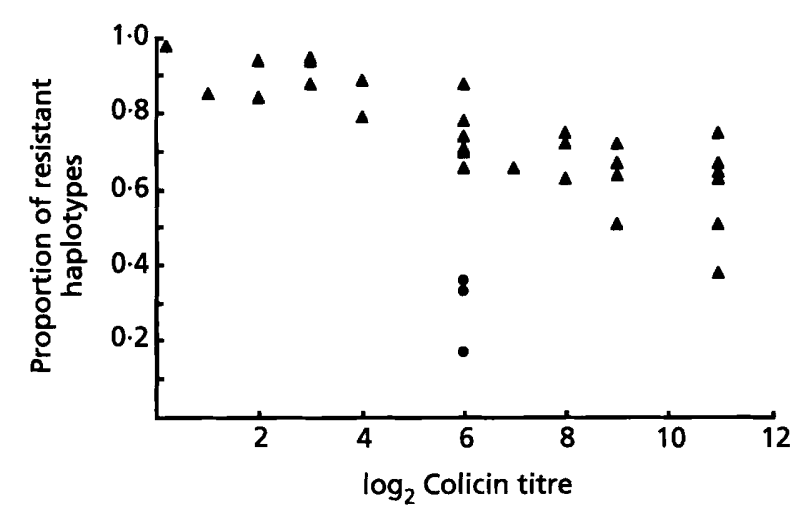

Fig. 2. Relationship between the fraction of the $88 \mathrm{E}$. coli haplotypes that are resistant to the colicins produced by each of the 36 colicinogenic $E$. coli haplotypes and the titre of colicin produced by each colicinogenic strain. The solid circles represent three strains known to produce both colicin E2 and another unidentified colicin. See text for further details.

haplotypes were resistant to the colicin being produced by strain 79 , while $51 \%$ of the haplotypes were resistant to the colicin produced by strain 243. A significant amount of the variation in resistance to a particular colicin-producing haplotype can be explained by the titre of colicin being produced by that haplotype (Fig. 2). Regressing the fraction of haplotypes resistant to a particular colicinogenic haplotype against the titre of colicin $\left(\log _{2}\right)$ produced by that haplotype revealed that $30 \%$ of the variation in resistance can be explained by colicin titre (linear regression: $R^{2}=0 \cdot 30, F_{(1,34)}=14.75$, $P<0.001)$. There are three obvious outliers in the data presented in Fig. 2, these haplotypes are thought to be producing colicin E2 together with an unidentified colicin. When these colicinogenic haplotypes are dropped from the analysis, colicin titre explains $65 \%$ of the variation in resistance $\left(R^{2}=0.65, F_{(1,31)}=57 \cdot 55\right.$,

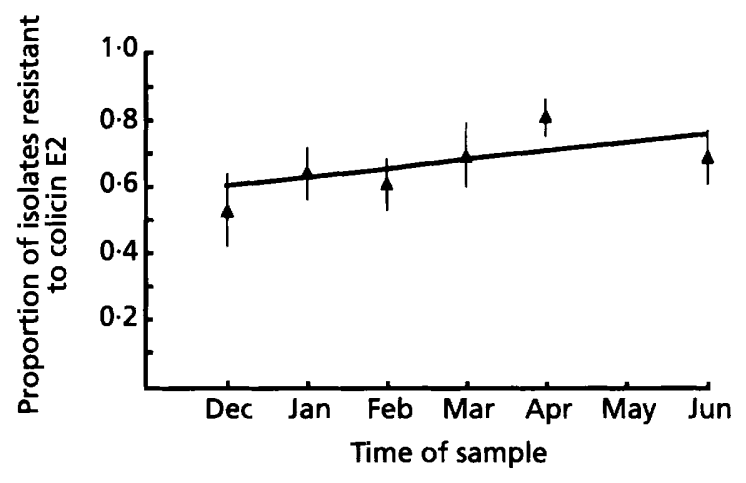

Fig. 3. Change in the resistance of $E$. coli isolates from $M$. domesticus to colicin E2 through time. Symbols represent the mean susceptibility to colicin E2 of the isolates not producing colicin E2 (vertical lines represent $95 \%$ confidence interval). The solid line represents the estimated change in resistance through time using linear regression.

$P<0.001)$. The same analysis using those strains known to produce only colicin E2 showed that $64 \%$ of the variation in resistance can be explained by the amount of colicin being produced by each haplotype $\left(R^{2}=0.64\right.$, $\left.F_{(1,11)}=19.76, P<0.001\right)$.

On average, a haplotype was resistant to $73 \%$ of the colicins being produced in this population of $E$. coli, with some haplotypes being resistant to all co-occurring colicins while others were susceptible to all colicins. On average, colicin-producing haplotypes were as resistant to co-occurring colicins $(75 \%)$ as non-producing haplotypes $\left(71 \%\right.$ ) (ANOVA: $\left.F_{(1,86)}=0.36, P>0.55\right)$. There was a significant amount of variation in the resistance of the colicinogenic haplotypes to co-occurring colicins $\left(F_{(3,23)}=9.24, P<0.001\right)$. The haplotypes producing colicin E2 were resistant to $81 \%$ of the non-homologous colicins; those with an E2/E7 phenotype or those producing E2 plus an unknown colicin were resistant to $86 \%$ of the colicinogenic haplotypes, whilst haplotypes producing only colicin Ia were resistant to $37 \%$ of the colicinogenic haplotypes.

The frequency of isolates producing colicin E2 was shown to decline through time. To determine if any change in resistance to colicin E2 could be detected the data were analysed in the following manner. First, all of the isolates producing colicin E2 were discarded from the analysis; the remaining isolates were scored with regard to their resistance to extracts of the 13 haplotypes known to produce the E2 colicin. The fraction of E2 extracts to which the isolates were resistant increased through time (linear regression: $F_{(1,325)}=9.86$, $P<0.002)$. A slope significantly greater than zero was found even when the April sample was excluded from the analysis. At the first sample, the isolates not producing colicin E2 were, on average, resistant to about half of the 13 colicin E2 extracts; by the last sample date these isolates were resistant to more than two-thirds of the extracts (Fig. 3). 


\section{DISCUSSION}

The number of colicin phenotype/genotype combinations (a minimum of nine) in this collection of $E$. coli is comparable to that previously determined for other collections of $E$. coli (Riley \& Gordon, 1996). Riley \& Gordon (1996) observed that the relative abundance of different colicin types varied substantially between strain collections. The results of this study reinforce this observation. Colicin E2 was by far the most abundant colicin type found, both in terms of the fraction of haplotypes or isolates. This is the first time that a nuclease colicin has been found at such high frequencies; pore-forming colicins are usually the dominant type (Riley \& Gordon, 1996; Tan \& Riley, 1997). Colla appears to be the one colicin that is regularly observed, as it has been found in four out of five surveys (Riley $\&$ Gordon, 1996; this study)

On average, the strains in this population were resistant to about three-quarters of the co-occurring colicins, a level similar to that observed in previous studies (Riley \& Gordon, 1996). There was no obvious relationship between the relative abundance of a particular colicin and the frequency of resistance to that colicin in this population. Among haplotypes, resistance to colicins varies considerably with some haplotypes being susceptible to all co-occurring colicins while others are completely resistant. It is not known how the assay conditions (exponentially growing cells in rich media) used in this study to assess colicin resistance reflect the conditions experienced by cells inhabiting the lower intestine. The negative relationship observed between colicin resistance and colicin titre (Fig. 2) may be due to the phenomenon of colicin tolerance. Resistance to colicins is thought to be due to the loss of the surface receptor to which the colicin binds. In addition to complete resistance, cells may also become tolerant to some colicins through changes in the mechanisms by which colicins are transported into the cell (Nomura \& Witten, 1967). Tolerance mechanisms can be overwhelmed if the cell is exposed to large amounts of colicin. However, the fact that, on average, over $50 \%$ of the haplotypes are resistant even when exposed to extracts with the highest colicin titres supports the observation that the majority of strains in this population of E. coli are resistant to the co-occurring colicins.

The most significant results of this study were the observed changes through time in the frequency of colicinogeny and the frequency of resistance to the most common colicin in this population of $E$. coli. The frequency of colicinogenic isolates declined by about $30 \%$ over the 7 months of the study. As well as the overall frequency of colicinogeny declining, the frequency of isolates producing colicin E2, the most common colicin in this population, declined over this same period. Concurrently, the resistance of isolates (those not harbouring the ColE2 plasmid) to colicin E2 increased by about $17 \%$. These observations are discussed below in light of our understanding of the dynamics of colicinogeny arising from mathematical models of this phenomenon. Two hypotheses to explain the observed results are proposed.

The first hypothesis concerns the dynamics of the interactions occurring between colicinogenic, resistant and susceptible populations within a host. Mathematical models of the dynamics of colicinogeny, in unstructured or structured environments, as well as in vitro studies, have conclusively demonstrated the frequency-dependent nature of colicin-producing and sensitive cell population interactions (Chao \& Levin, 1981; Levin, 1988; Frank, 1994). When attempting to establish in a habitat, the common strain, colicinogenic or noncolicinogenic, will tend to win. Models that assume mass action dynamics in an unstructured environment have demonstrated that colicinogenic and sensitive cell populations cannot co-exist, one population will eventually displace the other (Levin, 1988; Frank, 1994). This is not the case in structured environments where colicinogenic and sensitive cell populations can co-exist (Frank, 1994; Durrett \& Levin, 1997).

The expansion of mass action models in unstructured habitats to include a resistant cell population show that the three cell populations cannot co-exist (unpublished results). Given appropriate initial conditions, the colicinogenic population will displace the susceptible cell population. If resistance evolves in the susceptible population, resistant cells will increase in frequency and displace the colicinogenic population. Resistance is thought to impose a fitness cost as a result of the loss of surface receptors used for the uptake of essential compounds such as vitamins (Di Masi et al., 1973; Riley \& Gordon, 1996). In the absence of the colicin, as a consequence of the cost of resistance, reversion from resistance to susceptibility will occur and sensitive cells will displace the resistant cell population. Although mathematical models of colicinogenic, sensitive and resistant cell populations interacting in a structured environment have not been developed, it may be that such models would demonstrate that the co-existence of these three populations is possible. A recent theoretical study provides some support for this assumption. Durrett \& Levin (1997) investigated the dynamics of three populations of cells interacting in a structured environment. The three populations were colicinogenic, colicin-susceptible and a population of colicinogenic cells producing the same colicin but to a lesser extent than the primary colicinogenic population, and which, as a consequence, had a growth rate advantage over the colicinogenic strain. Simulations of this model demonstrated that long-term persistence of the three populations could occur. A resistant cell is, in some respects, like a non-producing colicinogenic cell - it would not be killed by the colicin.

With co-existence of colicinogeny, resistant and sensitive states, cyclic changes in the relative abundance of these three states may occur. Such cyclic behaviour could result from the inherent frequency-dependent nature of the dynamics of colicinogenic cell-sensitive cell interactions coupled with the changes in the fitness 
of resistant cells in the presence versus the absence of colicin. Under such a scenario, relatively small changes in the frequency of resistance, such as that observed for colicin E2 (from about 50 to $75 \%$ ), might be sufficient to reverse the advantage of colicinogeny and cause a substantial decline in the frequency of colicinogenic cells and a concomitant increase in the frequency of noncolicinogenic cells.

The observed changes in the relative frequency of colicinogenic, resistant and susceptible populations might be explained solely on the basis of the interactions occurring among these populations within a host. This second hypothesis is more concerned with the betweenhost dynamics of colicinogenic and non-colicinogenic populations. Concurrent with the change in the frequency of colicinogeny observed in the E. coli population, dramatic changes were occurring in the host population. In this region of Australia house mouse numbers regularly attain plague status, an event which occurred during the course of this study (Gordon, 1997). Mouse densities at the peak of a plague and densities during the inter-plague periods can differ by two to four orders of magnitude (Berry \& Bronson, 1992). Why might a change in host population density result in a change in the frequency of colicinogeny?

At the start of the study mouse densities were near their inter-plague low and peaked in April/May. Thus, while colicinogeny was declining in frequency, a large number of potential hosts were being born. Gordon (1997) has shown that as the host population ages both the clonal diversity and total number of clones increases with host age. Perhaps, as mice are born and acquiring their E. coli flora non-colicinogenic strains are more likely to establish than colicinogenic strains. Therefore, in times of a plague when rates of mouse recruitment are large, non-colicinogenic strains are at an advantage. During inter-plague periods when recruitment is low and the mouse population is dominated by hosts with an established gut flora, the advantage switches to colicinogenic strains.

Theoretical models provide some support for this hypothesis (Frank, 1994). Frank (1994) demonstrated that when non-colicinogenic and colicinogenic strains are both equally rare and invade a structured, but unsaturated environment (neither population at carrying capacity), then the non-colicinogenic strain is more likely to establish and displace the colicinogenic strain. This result is a consequence of the growth rate advantage enjoyed by the non-colicinogenic strain. This advantage occurs because there is a cost to colicin production, for example cell lysis, which reduces the net growth rate of the colicinogenic population. By contrast, when one of the strains is rare while the other is common and total population numbers are at the carrying capacity of the environment, then colicin producers are more likely to invade the habitat than are susceptible cells.

To summarize, the growth rate advantage of the noncolicinogenic strain relative to the colicinogenic strain could result in non-colicinogenic strains being more likely to establish in new-born hosts with a gut flora in its early succession stage. Therefore, during periods when recruitment rates to the host population are large, non-colicinogenic strains are at an advantage. Once established, the non-colicinogenic strain is not easily displaced as it now derives its advantage by being common. However, as the host ages, the non-colicinogenic strain is eventually displaced. During periods of low host recruitment the non-colicinogenic strain loses the advantage it has when attempting to invade new hosts and is unable to invade hosts with an established colicinogenic strain. Under this hypothesis, the change in the frequency of colicinogeny observed is a consequence of host dynamics and not the observed change in the frequency of resistance.

At present, there are insufficient data to distinguish between these two hypotheses. Regardless, this study has demonstrated that colicinogenic strains can co-exist in the face of a high frequency of strains resistant to cooccurring colicins and that the change in frequency of colicinogenic strains implies a change in fitness of these strains. Distinguishing between these hypotheses will be difficult. Mathematical models will need to be developed and in vitro experiments undertaken involving colicinogenic, susceptible and resistant populations interacting in a structured environment to determine if cyclic changes in relative abundance of these three cell populations can arise. Further in vivo experimental work is required to test whether non-colicinogenic strains are indeed at an advantage when invading hosts with a gut flora in its early succession stages whilst colicinogeny confers an advantage when attempting to establish in hosts with an established flora.

\section{ACKNOWLEDGEMENTS}

This study could not have been undertaken without the assistance of Grant Singleton and other members of the Rodent Control group of the Division of Wildlife and Ecology, Commonwealth Science and Industry Research Organization. The technical assistance of Frances FitzGibbon was invaluable. This study was funded by the Australian Research Council. Additional funds were provided by NIH FIRST and NSF PYI awards to M.A.R.

\section{REFERENCES}

Berry, R. J. \& Bronson, F. H. (1992). Life history and bioeconomy of the house mouse. Biol Rev 67, 519-550.

Chao, L. \& Levin, B. R. (1981). Structured habitats and the evolution of anticompetitor toxins in bacteria. Proc Natl Acad Sci USA 78, 6324-6328.

Cooke, M., Hettiaratchy, G. T. \& Buck, A. C. (1972). The fate of ingested Escherichia coli in normal persons. J Med Microbiol 5, 361-369.

Craven, J. A. \& Barnum, D. A. (1971). Distribution of porcine fecal coliflora throughout a barn. Can J Comp Med 35, 274-278.

Di Masi, D. R., White, J. C., Schnaitman, C. A. \& Bradbeer, C. (1973). Transport of vitamin $B_{12}$ in Esherichia coli: common 
receptor sites for vitamin $B_{12}$ and the $E$ colicins on the outer membrane of the cell envelope. J Bacteriol 115, 506-513.

Durrett, R. \& Levin, S. (1997). Allelopathy in spatially distributed populations. J Theor Biol 185, 165-171.

Feldgarden, M., Golden, S., Wilson, H. \& Riley, M. A. (1995). Can phage defence maintain colicin plasmids in Escherichia coli? Microbiology 141, 2977-2984.

Frank, S. A. (1994). Spatial polymorphism of bacteriocins and other allelopathic traits. Evol Ecol 8, 369-386.

Gordon, D. M. (1997). The genetic structure of Escherichia coli populations in feral house mice. Microbiology 143, 2039-2046.

Levin, B. R. (1988). Frequency-dependent selection in bacterial populations. Philos Trans R Soc Lond B Biol Sci 319, 459-472.

Luria, S. E. \& Suit, J. I. (1987). Colicins and col plasmids. In Escherichia coli and Salmonella typhimurium: Cellular and Molecular Biology, pp. 1615-1622. Edited by F. C. Neidhardt and others. Washington, DC: American Society for Microbiology.

Nomura, M. \& Witten, C. (1967). Interactions of colicins with bacterial cells. III. Colicin tolerant mutations in Escherichia coli. J Bacteriol 94, 1093-1111.

Power, D. A. \& McCuen, P. L. (1988). Manual of BBL Products and Laboratory Procedures, 6th edn. Cockeysville, MD: Becton Dickinson Microbial Systems.
Pugsley, A. P. (1984). The ins and outs of colicins. Microbiol Sci 1, 168-175, 203-205.

Pugsley, A. P. \& Oudega, B. (1987). Methods of studying colicins and their plasmids. In Plasmids, a Practical Approach, pp. 105-161. Edited by K. G. Hardy. Oxford: IRL Press.

Riley, M. A. \& Gordon, D. M. (1992). A survey of Col plasmids in natural isolates of Escherichia coli and an investigation into the stability of Col-plasmid lineages. J Gen Microbiol 138, $1345-1352$.

Riley, M. A. \& Gordon, D. M. (1996). The ecology and evolution of bacteriocins. J Indust Microbiol 17, 151-158.

Tadd, A. D. \& Hurst, A. (1961). The effect of feeding colicinogenic Escherichia coli on the intestinal $E$. coli of early weaned pigs. $J$ Appl Bacteriol 24, 222-228.

Tan, Y. \& Riley, M. A. (1997). Nucleotide polymorphism in colicin E2 gene clusters: evidence for non neutral evolution. Mol Biol Evol 14, 666-673.

Wexler, M., Gordon, D. M. \& Murphy, P. J. (1996). Genetic relationships among rhizopine-producing Rhizobium strains. Microbiology 142, 1059-1066.

Received 13 January 1998; revised 1 April 1998; accepted 17 April 1998. 